\title{
Assessment of the Use of Ultrasound in Local Anesthesia for Ophthalmic Surgery
}

Ibrahim Hassan El-Banna, Ibrahim Abdel-Ghany, Amr Mohmoud Montaser, Hadeel Magdy Abdel-Hameed

Anesthesiology Department, Faculty of Medicine, Ain Shams University, Cairo, Egypt

*Correspondence: Ibrahim H. Khalil, E-mail: Ibrahimhassan2002@ hotmail.com, Mobile:00201009181878

\begin{abstract}
Eye surgery is the most common surgery in the elderly. Many ophthalmic procedures, such as cataract extraction can be performed safely in an outpatient setting, using regional anesthesia and mild sedation. The number of outpatient ophthalmic procedures will increase as the population continues to age. Advantages of regional anesthesia over general anesthesia are numerous; it is generally safer with less incidence of complications and less bleeding.

Aim: The purpose of this thesis is to evaluate the use of ultrasonography in the performance of local anesthesia for ophthalmic surgery. This assessment includes whether ultrasound will add to the safety of the technique and its success rate.

Patients and methods: After approval of our institutional ethics committee and obtaining a written informed consent, 100 adult patients having routine cataract extraction were divided randomly into: Group A (peribulbar anesthesia) and Group B (retrobulbar anesthesia), with 50 patients in each group. Each group was subdivided into two subgroups: In one the anesthesia was administered blindly, in the second using B-scan ultasonography, with 25 patients in each one. Patients randomly allocated to one of these four subgroups until the required number is reached in each group.

Results: Results of the current study demonstrated comparable degree of globe akinesia after 10 minutes $(\mathrm{p}=0.342)$. The majority of cases showed no globe movement after 10 minutes. Similarly, lid akinesia showed no significant difference between 4 groups $(p=0.082)$. This was accompanied by partial satisfaction of the majority of surgeons with the procedure; comparable in the 4 subgroups $(\mathrm{p}=0.270)$.

Conclusion: Peribulbar and retrobulbar regional anesthesia of the orbit during cataract surgery are safe procedures if blindly applied. Ultrasonography-guided needle injection doesn't add to the safety and/or efficacy of the procedure. Therefore, ultrasound guidance is not an advantage in orbital regional anesthesia; whether administered by the peribulbar or retrobulbar technique.
\end{abstract}

Keywords: Eye surgery, cataract surgeries, extraocular muscles, ophthalmic artery, orbit.

\section{Introduction}

Eye surgery is the most common surgery in the elderly. Many ophthalmic procedures, such as cataract extraction, corneal transplants, trabeculectomy, lid surgery, and even viterectomy or repair of a detached retina can be performed safely in an outpatient setting, using regional anesthesia and mild sedation. The number of outpatient ophthalmic procedures will increase as health-care costs are contained and the population continues to age. Advantages of regional anesthesia over general anesthesia are numerous; it is generally safer with less incidence of postoperative nausea and vomiting, postoperative restlessness, post-operative lung, cardiac and cerebro-vascular complications and less bleeding ${ }^{(\mathbf{1})}$.
Peribulbar, retrobulbar and subTenon's techniques are widely used methods of regional anesthesia in ocular surgery. Recently, using of high resolution ultrasound B scanning which can identify the needles and cannulas is used in regional anesthesia. It can be also used in ophthalmic block to demonstrate the distribution of the local anesthetic solution. Its use showed that using retrobulbar and sub-Tenon's injection, the anesthetic solution accumulated almost directly into the muscle cone and, in contrast, after peribulbar injection, the anesthetic fluid spread from the orbital fat into the muscle cone $\mathrm{e}^{(2)}$

Aim: Evaluate the use of ultrasonography in the performance of local anesthesia for ophthalmic surgery. 


\section{Patients and methods}

Ethical and approval statements: After approval of our Institutional Ethics Committee and obtaining a written informed consent, 100 adult patients having routine cataract extraction were studied.

100 patients were scheduled to undergo a cataract extraction surgery under peribulbar and retrobulbar block with an age ranging between 25 and 70 years, of both sexes and had an ASA physical class of I or II were included.

Patients excluded were those who refused local anesthesia, had known or suspected allergies or sensitivities to amide local anesthetics, had evidence of soft tissue infection near the proposed injection site, had known or suspected bleeding tendencies, suffered glaucoma, were uncooperative or claustrophobics, and those with communication barriers.

Statistical analysis: Data will be collected and statistically analyzed using analysis of two way (ANOVA) for the observed quantitative parameters which are: The distance from the needle tip to the globe, the length of needle introduced, the depth of the globe and orbit, the volume injected, akinesia score and intraocular pressure immediately and 10 minutes after injection. The Chi-square test (X2) will be used for qualitative data which are: postoperative pain score hourly for 4 hours, surgical condition (satisfactory or unsatisfactory), incidence of hemorrhage (yes or no) and patient satisfaction with the technique (yes or no). Then data will be expressed as mean + SD (standard Deviation). Benferroni test will be performed to isolate the source of significance. A p value less than 0.05 $(p<0.05)$ will be considered statistically significant.

Patients were randomly allocated in one of the following groups:

Group I (PB): Received a peribulbar block blindly

Group II (PG): Received a peribulbar block using ultrasonography.
Group III (RB): Received a retrobulbar block blindly.

Group IV (RG): Received a retrobulbar block using ultrasonography.

\section{Techniques used:}

\section{Single-Injection Peribulbar (Extraconal) Block}

we administered peribulbar blocks in the following manner: After application of topical benoxinate hydrochloride minims $0.4 \%$ and light sedation with midazolam 1 to $3 \mathrm{mg}$, and occasionally, fentanyl 25 to $50 \mathrm{mcg}$, a short-beveled, peribulbar needle (23 gauge,31 mm, Steriseal Ophthalmic Cannula) using an inferolateral approach. The patients were asked to keep their eyes open and maintain a fixed forward gaze during the needle placement to aid the detection of unintentional contact between the needle and the sclera. Once the needle was in place and the anesthesiologist was ready to inject, the patients were asked to close their eyelid. Then, a linear ultrasound (alcon, USA) transducer (3- to $12-\mathrm{MHz}$ linear array ultrasound probe HD), covered by a thin layer of sterile conductivity gel, was placed over the eyelid. The injection then took place.

\section{Retro-bulbar (Inra-conal) block}

The needle is advanced to enter within the cone of muscles posterior to the globe, taking care not to cross the mid-sagittal plane of the eye. While visually and digitally monitoring the increased orbital volume and intraconal pressure (globe between index finger and thumb of the non-injecting hand), 3-4 $\mathrm{ml}$ of the anesthetic (xylocain 2\% and bupivicain $0.5 \%$ equal amounts with 150 I.U Hyalurinidase) is injected slowly over a 1 minute period until a bulging of the superior orbital sulcus with filling out of the upper eye lid crease and some degree of ptosis is seen.

The local anesthetic mixture consisted of equal proportions of lidocaine $2 \%$ and bubivacine $0.5 \%$ with a hyaluranidase concentration of $7.5 \mathrm{U} / \mathrm{mL}$. No compression of the eye was performed after block placement. The maximal volume of local anesthetic allowed was 10 
$\mathrm{mL}$ (corresponding to the current practice in our institution). Real-time visualization of local anesthetic spread was done, as well as continuous monitoring of the needle tip during the block in the ultrasound group.

\section{Block Evaluation}

During the injection and after 10 minutes of completion of the block, the anesthesiologist performing the block was asked to evaluate whether the spread of local anesthetic was favorable/ intraconal, unfavorable/extraconal, or uncertain. Ten minutes after completion of the block, the anesthesiologist evaluated the degree of akinesia and was allowed to perform a secondary or supplementary block in cases where akinesia was insufficient. Before the start of the surgery.

In each group, the onset of akinesia, duration of procedure, recovery of akinesia and duration of analgesia were documented:

1. Globe akinesia: Score* minutes after injection)

Time between onset and full effect

2. Lid akinesia:Score $* *$ (10 minutes after injection)

Time between onset and full effect

3. Patient satisfaction: (during injection) Indicated by pain perception on visual analogue score $(0=$ no pain, $10=$ the worst) score 5 or less was considered unsatisfied.

4. Surgeon satisfaction: Indicated by topup requirement

5. Intraocular pressure (10 minutes after injection)

6. Complications, subconjunctival retrobulbar hemorrhage and intramuscular spread.

* Globe Akinesia score

** Lid Akinesia Score

Full movement 3

Full

movement 2

Moderate movement 2

Flicker

1
Flicker 1 No Movement 0

No movement 0

\section{Results}

The study involved 100 adults undergoing routine cataract extraction divided into two groups according to the type of anesthesia; peribulbar anesthesia groups and retrobulbar anesthesia group. Each group was subdivided into two subgroups; one for blindly administered anesthesia and the second for ultrasoundguided anesthesia. Thus, we have 4 groups: Peribulbar blind group (PB), Peribulbar ultrasound guided group (PG), Retrobulbar blind group (RB) and Retrobulbar ultrasound guided group (RG).

The four groups were comparable in age, sex and side of lesion. Table 1 shows the mean age and range of the four groups. There was no significant difference in age between the 4 groups $(p=0.758)$.

Table 1: mean age and range of the four studied groups

\begin{tabular}{lcc}
\hline & Mean \pm SD & Range \\
\hline PB group & $46.5 \pm 12.9$ & $25-68$ \\
PG group & $48.5 \pm 14.4$ & $26-71$ \\
RB group & $51 \pm 10.8$ & $30-72$ \\
RG group & $51 \pm 10.3$ & $31-71$ \\
\hline
\end{tabular}

Table 2: Sex distribution in four studied groups

\begin{tabular}{crc}
\hline & Male & Female \\
\hline PB group & $60 \%$ & $40 \%$ \\
PG group & $52 \%$ & $48 \%$ \\
RB group & $44 \%$ & $56 \%$ \\
RG group & $48 \%$ & $52 \%$ \\
\hline
\end{tabular}

Table 2 shows no significant difference between the four groups regarding sex $(\mathrm{p}=0.705)$.

Table 3: side of the lesion in the four studied groups

\begin{tabular}{ccc}
\hline & Right & Left \\
\hline PB group & $52 \%$ & $48 \%$ \\
PG group & $56 \%$ & $44 \%$ \\
RB group & $56 \%$ & $44 \%$ \\
RG group & $56 \%$ & $44 \%$ \\
\hline
\end{tabular}

Table 3 shows no significant difference between the 4 groups regarding side of the lesion $(\mathrm{p}=0.989)$. Table 7 shows the mean and range of the axial length in the four groups. There was no significant 
difference in axial length between the 4 groups $(\mathrm{p}=0.512)$.

Table 4: Axial length of the four studied groups

\begin{tabular}{lcc}
\hline & Mean \pm SD & Range \\
\hline PB group & $25.0 \pm 1.9$ & $22.0-29.0$ \\
PG group & $25.0 \pm 1.2$ & $23.0-28.0$ \\
RB group & $25.0 \pm 1.2$ & $23.0-28.0$ \\
RG group & $25.5 \pm 1.2$ & $23.0-28.0$ \\
\hline
\end{tabular}

Table 5: Degree of globe akinesia after 10 minutes in the 4 studied groups

\begin{tabular}{|c|c|c|c|c|}
\hline & $\begin{array}{l}\text { PB } \\
\text { group }\end{array}$ & $\begin{array}{l}\mathrm{PG} \\
\text { group }\end{array}$ & $\begin{array}{l}\mathrm{RB} \\
\text { group }\end{array}$ & $\begin{array}{c}\mathrm{RG} \\
\text { group }\end{array}$ \\
\hline $\begin{array}{l}\text { No } \\
\text { movements }\end{array}$ & $\begin{array}{c}15 \\
(60 \%)\end{array}$ & $\begin{array}{c}18 \\
(72 \%)\end{array}$ & $\begin{array}{c}15 \\
(60 \%)\end{array}$ & $\begin{array}{c}19 \\
(76 \%)\end{array}$ \\
\hline & $5(20 \%)$ & $3(12 \%)$ & $8(32 \%)$ & $6(24 \%)$ \\
\hline $\begin{array}{l}\text { moveme } \\
\text { Full }\end{array}$ & $3(12 \%)$ & $3(12 \%)$ & $2(8 \%)$ & $0(0 \%)$ \\
\hline movement & $2(8 \%)$ & $1(4 \%)$ & $0(0 \%)$ & $0(0 \%)$ \\
\hline
\end{tabular}

Table 5 shows that the 4 groups were comparable regarding degree of globe akinesia after 10 minutes $(\mathrm{p}=0.342)$. The majority of cases showed no globe movement after 10 minutes. Peribulbar cases failed to stabilize the globe in 2 cases $(8 \%)$ of the blindly anesthetized group and in one case of the ultrasoundguided group. This was not observed in the retrobulbar groups (Figure 1).

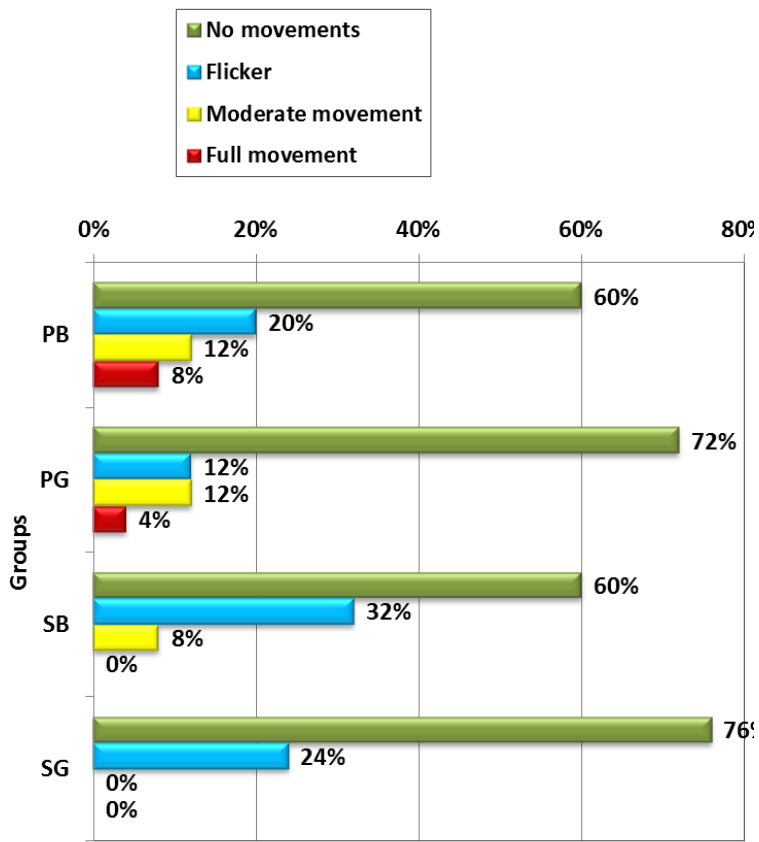

Figure 1: Degree of globe akinesia in the 4 studied groups
Table 6: Degree of lid akinesia after 10 minutes in the 4 studied groups

\begin{tabular}{lcccc}
\hline & $\begin{array}{c}\text { PB } \\
\text { group }\end{array}$ & $\begin{array}{c}\text { PG } \\
\text { group }\end{array}$ & $\begin{array}{c}\text { RB } \\
\text { group }\end{array}$ & $\begin{array}{c}\text { RG } \\
\text { group }\end{array}$ \\
\hline No & 19 & 24 & 24 & 23 \\
movements & $(76 \%)$ & $(96 \%)$ & $(96 \%)$ & $(92 \%)$ \\
Flicker & $6(24 \%)$ & $1(4 \%)$ & $1(4 \%)$ & $2(8 \%)$ \\
\hline
\end{tabular}

There was no significant difference between 4 groups regarding degree of lid akinesia after 10 minutes $(\mathrm{p}=0.082)$.

(Table 6, Figure 1).

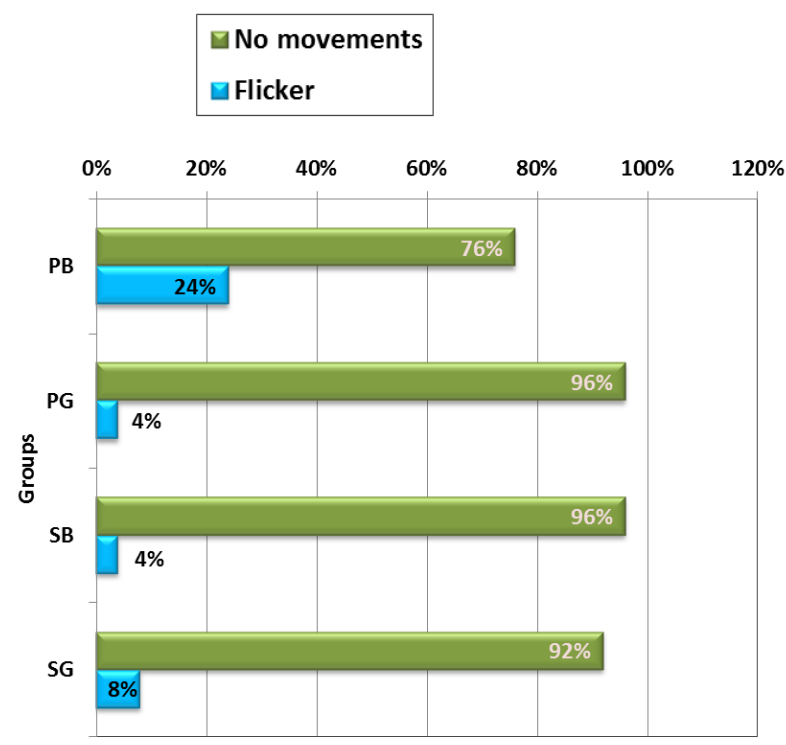

Figure 2: Degree of lid akinesia in the 4 studied groups

Complications of anesthetic injection were relatively few in the 4 groups (Table $\left.{ }_{80}: 10\right)$. Chemosis was observed in a total of 12 cases, 4 in PB, 2 in PG, 4 in $\mathrm{SB}$ and 2 in SG group. The guided groups showed less frequency of chemosis (Figure 29), but the difference was not significant ( $\mathrm{p}=$ 0.744). Subconjunctival hemorrhage was relatively uncommon. It was observed in 2 cases of PB and SB groups and one case of SG group (Figure 2). The difference between the 4 groups was not statistically significant $(\mathrm{p}=0.751)$. It was noted that retrobulbar hemorrhage occurred in only 3 cases; all of them in PG group ( $\mathrm{p}=0.026)$. Accidental intramuscular injection occurred in 18 cases, with no significant difference between the 4 groups $(\mathrm{p}=$ 0.820 ). (figure 2 ) There was no case of perforation, drug allergy or systemic toxicity in the 4 groups. 
Table 10: Frequency of complications in the 4 studied groups

\begin{tabular}{lcccc}
\hline & $\begin{array}{c}\text { PB } \\
\text { group }\end{array}$ & $\begin{array}{c}\text { PG } \\
\text { group }\end{array}$ & $\begin{array}{c}\text { RB } \\
\text { group }\end{array}$ & $\begin{array}{c}\text { RG } \\
\text { group }\end{array}$ \\
\hline Chemosis & 4 & 2 & 4 & \\
Subconjunctival & $(16 \%)$ & $(8 \%)$ & $(16 \%)$ & $2(8 \%)$ \\
haemorrhage & 2 & 0 & 2 & \\
Retrobulbar & $(8 \%)$ & $(0 \%)$ & $(8 \%)$ & $1(4 \%)$ \\
haemorrhage & 0 & 3 & 0 & \\
Intramuscular & 6 & $(12 \%)$ & $(0 \%)$ & $0(0 \%)$ \\
injection & $(24 \%)$ & $(12 \%)$ & $(16 \%)$ & $(20 \%)$ \\
\hline
\end{tabular}

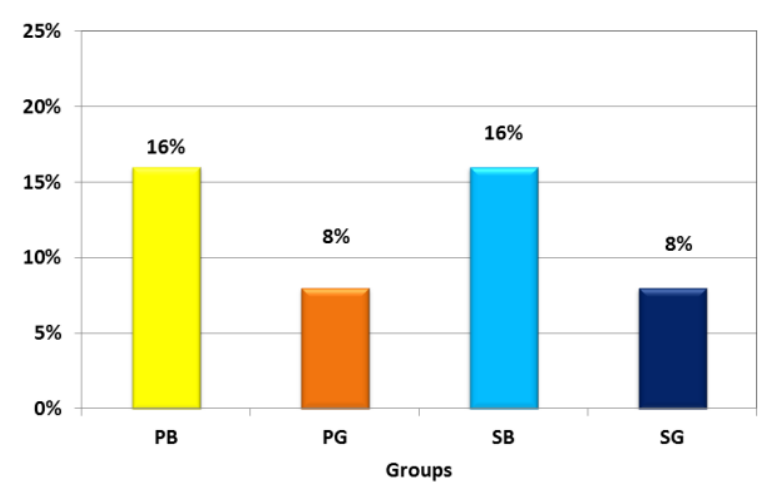

Figure 3: Frequency of chemosis in the 4 studied groups

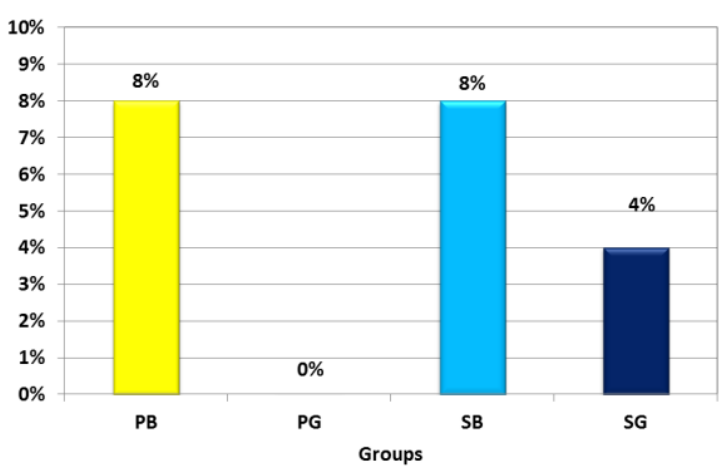

Figure 4: Frequency of subconjunctival hemorrhage in the 4 studied groups

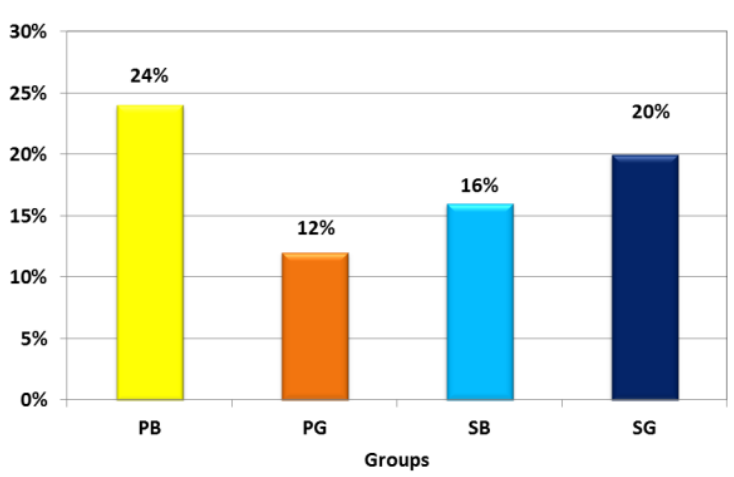

Figure 5: Frequency of intramuscular injection in the 4 studied groups

Table 11 showed degree of patient and surgeon satisfaction in the four satisfaction. Patient satisfaction was less in subtenon groups compared to peribulbar groups. Also it was less in ultrasoundguided groups relative to blindlyanesthetized group $(\mathrm{p}=0.001)$. The majority of surgeons were partially satisfied with the procedure in the 4 groups (Table 10). Larger number of surgeons was unsatisfied by the subtenon procedure compared to peribulbar procedure. However, there was no significant difference between the four groups in the degree of surgeon satisfaction $(p=0.270)$.

Table 11: Degree of patient satisfaction in the 4 studied groups

\begin{tabular}{ccccc}
\hline & $\begin{array}{c}\text { PB } \\
\text { group }\end{array}$ & $\begin{array}{c}\text { PG } \\
\text { group }\end{array}$ & $\begin{array}{c}\text { RB } \\
\text { group }\end{array}$ & $\begin{array}{c}\text { RG } \\
\text { group }\end{array}$ \\
\hline $\begin{array}{c}\text { Unsatisfi } \\
\text { ed }\end{array}$ & $5(20 \%)$ & 15 & 10 & 17 \\
Partially & $(60 \%)$ & $(40 \%)$ & $(68 \%)$ \\
satisfied & $8(32 \%)$ & $6(24 \%)$ & 11 & $7(28 \%)$ \\
Satisfied & 12 & $4(16 \%)$ & $4(16 \%)$ & $1(4 \%)$ \\
\hline
\end{tabular}

Table 12: Degree of surgeon satisfaction in the 4 studied groups

\begin{tabular}{ccccc} 
& $\begin{array}{c}\text { PB } \\
\text { group }\end{array}$ & $\begin{array}{c}\text { PG } \\
\text { group }\end{array}$ & $\begin{array}{c}\text { RB } \\
\text { group }\end{array}$ & $\begin{array}{c}\text { RG } \\
\text { group }\end{array}$ \\
\hline $\begin{array}{c}\text { Unsatisfi } \\
\text { ed }\end{array}$ & $2(8 \%)$ & $3(12 \%)$ & $6(24 \%)$ & $7(28 \%)$ \\
$\begin{array}{c}\text { Partially } \\
\text { satisfied }\end{array}$ & 23 & 22 & 19 & 18 \\
\hline
\end{tabular}

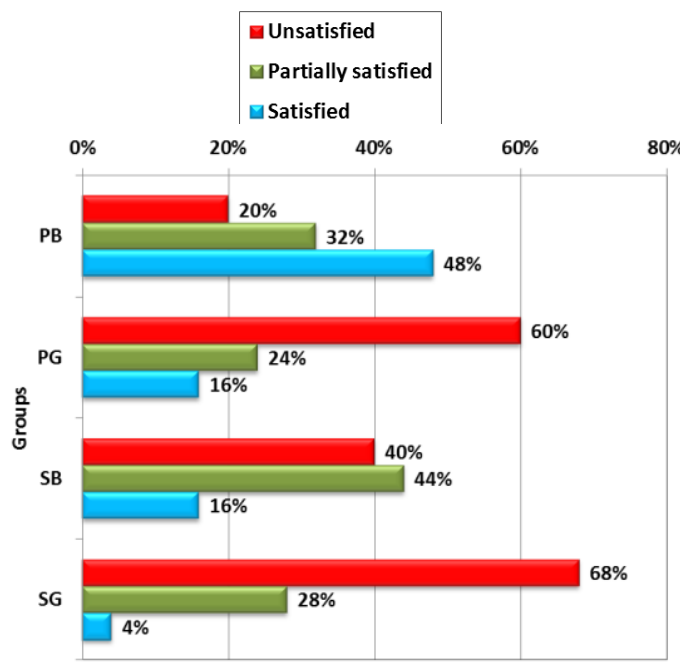

Figure 6: Degree of patient satisfaction in the 4 studied groups 


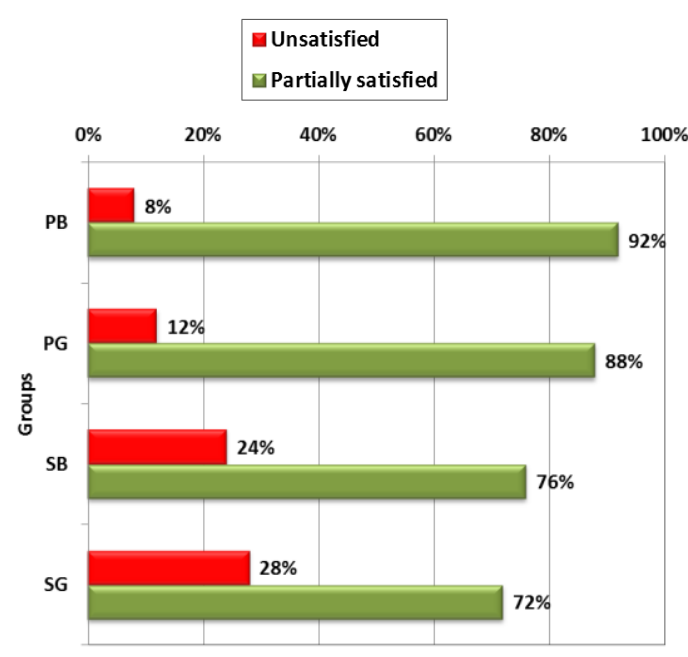

Figure 7: Degree of surgeon satisfaction in the 4 studied groups

\section{Discussion}

Although there are various techniques available to achieve anesthesia of the globe, each technique has its own advantages and disadvantages. The choice of the technique should be individualized based on specific needs of the patient, the nature and extent of eye surgery, and the anesthesiologist's and surgeon's preferences and skills. However, a thorough knowledge of the orbital anatomy and training are imperative for practicing safe orbital regional anesthesia. Peribulbar, retrobulbar and sub-Tenon's techniques are widely used methods of regional anesthesia in ocular surgery. Cataract extractions are performed under topical anesthesia but some of the patients need combined peribulbar and retrobulbar block or deep peribulbar for their eye surgery. Also for corneal transplantations and for vitreoretinal surgery, reliable sensory and motor blocks are needed ${ }^{(3)}$.

Compared with retrobulbar block, peribulbar block often is preferred because of lower risk of complications although the used anesthetic volume is greater, reliable analgesia and akinesia may also be achieved with a combination of peribulbar and retrobulbar techniques ${ }^{(4)}$. The subTenon's block is another technique for providing regional anesthesia for eye surgery. Serious complications, such as globe perforation, orbital hemorrhage and damage to extraocular muscles can occur with any of these techniques. The spread of the anesthetic agent anteriorly and posteriorly in the orbit plays an important role in producing sensory and motor blockade $^{(5)}$.

The purpose of this study was evaluation of the significance of ultrasonographic guidance of regional anesthesia for ophthalmic surgery; whether it adds to the safety of the technique or its success rate. We used high resolution B-scanning with standardized techniques to demonstrate the needle position in relation to the globe and to determine the distribution of the local anesthetic fluid. In addition we stressed the probability of any complications during injection.

The study involved 100 adults scheduled for routine cataract extraction randomly divided to regional anesthesia technique; a peribulbar groups $(\mathrm{n}=50)$ and a retobulbar group $(\mathrm{n}=50)$. Each group was randomly subdivided into two subgroups; one for blind technique and the other for US-guided technique.

The anesthetic technique was standardized in the two groups. Peribulbar and retrobulbar anesthesia were done with a $31 \mathrm{~mm}$ needle introduced through the inferotemporal point.

The use of ultrasound guidance in daily clinical practice requires high-level ultrasonographic equipment and a high degree of training. Anesthetists need to develop a thorough understanding of the anatomical structures involved, and they need to acquire both a solid grounding in ultrasound technology and the practical skills to visualize nerve structures. The successful performance of nerve block under direct ultrasonographic guidance varies with the operator's skill in a given regional anesthetic technique ${ }^{(6)}$.

Thus, the question to use or not to use US-guidance is a feasibility issue. Do we need this skill to be added to the anesthetist capabilities? Does it add to efficiency of akinesia and analgesia? Does it reduce complications? 
Results of the current study demonstrated comparable degree of globe akinesia after 10 minutes $(\mathrm{p}=0.342)$. The majority of cases showed no globe movement after 10 minutes. Similarly, lid akinesia showed no significant difference between 4 groups $(p=0.082)$. This was accompanied by partial satisfaction of the majority of surgeons with the procedure; comparable in the 4 subgroups $(\mathrm{p}=$ 0.270).

Complications of anesthetic injection were quite few in the 4 groups; mainly in the form of chemosis. The guided groups showed less frequency of chemosis, but the difference was not significant $(\mathrm{p}=$ 0.744). Three cases of peribulbar group developed retrobulbar hemorrhage. There was no case of perforation, drug allergy or systemic toxicity in the 4 groups. Patient satisfaction was less in the retrobulbar groups compared to peribulbar groups. Also, satisfaction was less in ultrasoundguided groups relative to blindlyanesthetized group $(\mathrm{p}=0.001)$.

Complications of blind needle passage are rare but often devastating. Perforations of the globe $^{(7)}$, damage to the optic nerve $^{(8)}$, persistent diplopia by direct injection of the anesthetic into the muscle $^{(9)}$, and potentially fatal consequences of local anaesthetic agents on the central nervous system $^{(\mathbf{1 0})}$ are described. Analysis of the closed claims database of the American Society of Anesthesiologists shows that eye blocks (retrobulbar and peribulbar) are the leading cause of claims compared with other peripheral nerve blocks, especially for closed claims with permanent disabling complications ${ }^{(11)}$.

To reduce the risk of intra-orbital or intraocular damage, other techniques have become popular. For peribulbar anesthesia, the local anesthetic is injected around the equator of the globe. However, even if the risk of globe perforation is lower than the reported incidences in retrobulbar blocks, there are still a certain number of globe perforations with this technique. Moreover, the peribulbar block has been shown to be less effective than the retrobulbar block ${ }^{(12)}$.
On the other hand, sub-Tenon's block, also known as parabulbar or episcleral block, has been reported to be very effective for eye surgery ${ }^{(13)}$. But with this block, complete akinesia of the eye cannot be achieved which is a disadvantage for operations close to the retina. Moreover, severe side-effects such as globe perforations, optic nerve damage, and brain stem anesthesia have also been reported with the sub-Tenon's block (Quantock CL, Goswami T. Death potentially secondary to sub-Tenon's block $^{(14)}$.

As in other areas of regional anesthesia, ultrasound-guided injection of local anesthesia might improve the quality and safety of peribulbar and sub-tenon anesthesia by visualization of the needle placement ${ }^{(15)}$.

Moreover, the key requirement for successful regional anesthetic blocks is to ensure optimal distribution of local anesthetic around nerve structures. This goal is most effectively achieved under sonographic visualization. Cadaver studies demonstrated that intra-conal and extraconal spaces are part of a common spreading space, and the orbital fat allows fluids to diffuse easily within the orbit ${ }^{(6)}$.

Consequently, we can say that ultrasound guidance is not an asset in orbital regional anesthesia; whether administered by the peribulbar or retrobulbar technique.

A relatively recent cadaveric study concluded that ultrasound-guided retrobulbar anesthesia technique has the potential to improve safety and efficacy of the procedure by direct visualization of the needle placement and the distribution of the injected fluid. Furthermore, the precise injection near the optic nerve could lead to a reduction of the amount of the local anesthetic needed with fewer related complications ${ }^{(16)}$.

However, it has been recognized that retrobulbar anesthesia - even if blindly performed - is known to be safe with a complication rate $<1 \%{ }^{(15)}$. It is believed that visualization of the needle with ultrasound can further improve safety and 
efficacy. This may be true when the risk of ocular perforation is high as in eyes with high myopia due to the increased axial length ${ }^{(17)}$. This should no longer be a problem when using ultrasound guidance because the needle tip can be tracked and guided along the sclera.

Peribulbar anesthesia should be safer relative to the retrobulbar approach. It encompasses introducing the needle into the extra-conal space of the orbit. It avoids traversing the cone muscles and entering the intra-conal space and its vital structures, including the globe, the optic nerve, and the central retinal artery.

To be as effective as retrobulbar technique, a relatively high volume of local anesthetic is injected into the extraconal space (usually $8-12 \mathrm{~mL})^{(\mathbf{1 8})}$. The local anesthetic injected into the extraconal space must spread into the intraconal space to provide adequate anesthesia and akinesia of the globe ${ }^{(19)}$.

This may explain the high proportion (24\%) of blindly anesthetized peribulbar group that shows flickering lid in the current study. This is because we inject 5 $\mathrm{ml}$ of the anesthetic solution.

A recent study used a median volume of local anesthetic to be injected in peribulbar anesthesia of $9 \mathrm{~mL}$. By using ultrasound in this study, authors demonstrated that, during attempted peribulbar (extra-conal) block, the instantaneous intra-conal spread occurs frequently. They found a strong association between intraconal spread and the effectiveness of the block in achieving akinesia and anesthesia ${ }^{(20)}$.

However, an anatomic study ${ }^{(21)}$ and a clinical radiologic investigation have shown that the spread of fluid in the orbit might be similar, regardless of the injection type (peribulbar or retrobulbar) ${ }^{(22)}$. Gayer et al. demonstrated that the local anesthetic injected into both spaces (i.e., intra-conal and extra-conal) was able to flow freely from one space to the other. Also found similar results using tomodensitometry in human cadavers ${ }^{(23)}$.
For assessing the debate over whether the peribulbar approach provides more effective and safer anesthesia for cataract surgery than retrobulbar block, a systematic review involving 6 clinical trials including 1438 participants was done. Authors found no evidence of any difference in pain perception or akinesia during surgery with either technique; both were largely effective. However, conjunctival chemosis was more common after peribulbar block $^{(24)}$. The current series documented relatively higher frequency of chemosis with peribulbar anesthesia.

We believe that the trivial effect of ultrasound guidance in the current study can be explained by the stable anatomic site of injection inside the bony orbital cavity. The inferomedial direction of injection in peribulbar cases inside the extra-conal space is quite far from the globe, optic nerve and vessels in the intraconal space. This makes blind needle insertion a relatively safe procedure.

Safety of real-time bedside ophthalmic ultrasound is another important issue to consider. The bioeffects of ultrasound on the eye must be considered before encouraging translational application and clinical use of sonography for ophthalmic anesthesia. Ultrasonic oscillating waves are essentially pulsed energy. They create both thermal and mechanical perturbations in tissue and can induce tissue heating and acoustic pressure. Two indices, thermal index (TI) and mechanical index (MI), are denotive of heat and mechanical agitation that may be generated by a particular ultrasonic transducer ${ }^{(25)}$.

Recognizing the special nature of orbital tissue, the FDA and Health Canada permit an MI of $\leq 1.9$ for all target tissues, with the exception of the eye $(\leq 0.23)$. Additionally, they recommend equipment that has a maximal achievable TI of 6.0; however, the limit for the eye is 1.0. The British Medical Ultrasound Society concurs that TI be no more than 1.0. Most commercially marketed ultrasound transducers do not comply with these recommendations ${ }^{(26)}$. 


\section{Conclusion}

We can conclude that peribulbar and retrobulbar regional anesthesia of the orbit during cataract surgery is safe procedures if blindly applied. Ultrasonography-guided needle injection doesn't add to the safety and/or efficacy of the procedure. Peribulbar block using $5 \mathrm{ml}$ of anesthetic drug seems less than required in almost $25 \%$ of cases, thus raising the injected volume up to $10 \mathrm{ml}$ may be a better choice to guarantee a satisfactory degree of akinesia. Therefore, ultrasound guidance is not an advantage in orbital regional anesthesia; whether administered by the peribulbar or retrobulbar technique.

\section{References}

1. Feldman MA (2009): Anesthesia for eye, ear, nose and throat surgery. Miller's Anesth., 7:2357-2388.

2. Chapman GA, Johnson D, Bodenham AR (2006): Visualisation of needle position using ultrasonography. Anaesthesia, 61(2):148-158.

3. Winder S, Ndwsmj C (1998): Vitreoretinal surgery after inadvertent globe penetration during local ocular anesthesia. Eye, 12:486-488.

4. Patton N, Malik TY, Aslam TM (2005): Sub-Tenon's anesthetic administration for cataract surgery: how much stays in? Anesth Analg., 101(4):1012-1014.

5. Atta HR (1996): Ophthalmic Ultrasound: A Practical Guide. Butterworth-Heinemann.

6. Marhofer P, Greher M, Kapral S (2004): Ultrasound guidance in regional anaesthesia. Br J Anaesth., 94(1):7-17.

7. Wearne MJ, Flaxel CJ, Gray P, Sullivan PM, Cooling RJ (1998): Vitreoretinal surgery after inadvertent globe penetration during local ocular anesthesia. 105(2):371-376.

Ophthalmology,

8. Pautler SE, Grizzard WS, Thompson LN, Wing GL (1986):
Blindness from retrobulbar injection into the optic nerve. Ophthalmic Surgery, Lasers Imaging Retin., 17(6):334-337.

9. Gómez-Arnau JI, Yangüela J, Gonzalez A et al. (2003): Anaesthesia-related diplopia after cataract surgery. $\mathrm{Br} J$ Anaesth., 90(2):189-193.

10. Javitt JC, Addiego R, Friedberg HL, Libonati MM, Leahy JJ (1987): Bran Stem Anesthesia after Retrobulbar Block. Ophthalmology, 94(6):718-724.

11. Lee LA, Domino KB (2005): Complications associated with peripheral nerve blocks: lessons from the ASA closed claims project. Int Anesthesiol Clin., 43(3):111-118.

12. Wadood AC, Dhillon B, Singh $\mathbf{J}$ (2002): Inadvertent ocular perforation and intravitreal injection of an anesthetic agent during retrobulbar injection. J Cataract Refract Surg., 28(3):562-565.

13. Stevens JD (1992): A new local anesthesia technique for cataract extraction by one quadrant subTenon's infiltration. $B r \quad J$ Ophthalmol., 76(11):670-674.

14. Kumar CM, Dodds C, McLure H, Chabria R (2004): A comparison of three sub-Tenon's cannulae. Eye, 18(9):873.

15. Davis DB, Mandel MR (1994): Efficacy and complication rate of 16,224 consecutive peribulbar blocks: a prospective multicenter study. $J$ Cataract Refract Surg., 20(3):327337.

16. Luyet $C$, Eichenberger U, Moriggl B, Remonda L, Greif $R$ (2008): Real-time visualization of ultrasoundguided retrobulbar blockade: an imaging study. $\mathrm{Br} \quad J$ Anaesth., 101(6):855-859.

17. Hay A, Flynn HW, Hoffman JI, Rivera AH (1991): Needle penetration of the globe during retrobulbar and peribulbar injections. 
Ophthalmology, 98(7):1017-1024.

18. Findl $O$, Dallinger $S$, Menapace $R$ et al. (1999): Effects of peribulbar anesthesia on ocular blood flow in patients undergoing cataract surgery. Am J Ophthalmol., 127(6):645-649.

19. Nouvellon $\mathbf{E}$, Cuvillon $\mathbf{P}$, Ripart $\mathbf{J}$ (2010): Regional anesthesia and eye surgery. Anesthesiol $J$ Am Soc Anesthesiol., 113(5):1236-1242.

20. Luyet C, Eng KT, Kertes PJ, Avila A, Muni RH, McHardy P (2012): Real-time evaluation of diffusion of the local anesthetic solution during peribulbar block using ultrasound imaging and clinical correlates of diffusion. Reg Anesth Pain Med., 37(4):455-459.

21. Ripart J, Lefrant JY, de La Coussaye JE, Prat-Pradal D, Vivien B, Eledjam JJ (2001): Peribulbar versus Retrobulbar Anesthesia for Ophthalmic SurgeryAn Anatomical Comparison of Extraconal and Intraconal Injections. Anesthesiol $J$ Am Soc Anesthesiol., 94(1):56-62.
22. Ropo A, Nikki P, Ruusuvaara $\mathbf{P}$, Kivisaari L (1991): Comparison of retrobulbar and periocular injections of lignocaine by computerised tomography. $\mathrm{Br} J$ Ophthalmol., 75(7):417-420.

23. Ortiz M, Valls $R$, Vallès $\mathbf{J}$, Blanco D, Vidal F (1995): Topography of peribulbar anesthesia. Reg Anesth., 20(4):337-342.

24. Alhassan MB, Kyari F, Ejere HOD (2008): Peribulbar versus retrobulbar anaesthesia for cataract surgery. Cochrane Database Syst Rev., 3(3):CD004083.

25. Abbott JG (1999): Rationale and derivation of MI and TI'a review1. Ultrasound Med Biol., 25(3):431-441.

26. Gayer S, Palte H, Kumar C, et al. (2009): Real-time visualization of ultrasound-guided retrobulbar blockade: an imaging study. $\mathrm{Br} J$ Anaesth., 102(4):561-562. 